\title{
Nursing safety management in onco-hematology pediatric wards
}

\author{
Gestão de segurança de enfermagem em enfermarias de onco-hematologia pediátrica \\ Gestión de seguridad de enfermería en habitaciones pediátricas onco-hematológicas
}

Marcelle Miranda da Silva ${ }^{1}$, Bruna Irene Cunha Curty ${ }^{2}$, Sabrina da Costa Machado Duarte ${ }^{1}$, Karen Gisela Moraes Zepeda $^{1}$

This study aimed at identifying how safety management is applied by nurses to manage the nursing care, and at analyzing their challenges in onco-hematology pediatric wards. Descriptive and qualitative research, conducted at the Instituto Estadual de Hematologia Arthur de Siqueira Cavalcanti, Rio de Janeiro, Brazil, in August 2013. Six nurses were interviewed, and the content analysis was used. The key aspects relate to the importance of training and continuing education, teamwork, with the challenges in the care of hospitalized children and particularities of the disease, and the systematization, use of instruments and protocols. For child safety, the relationship between the administration and support is critical to the quality of care.

Descriptors: Pediatric Nursing; Oncology; Patient Safety; Management.

Objetivou-se identificar como a gestão de segurança é aplicada pelo enfermeiro no âmbito do gerenciamento do cuidado de enfermagem, e analisar os seus desafios nas enfermarias de onco-hematologia pediátrica. Pesquisa descritiva, qualitativa, realizada no Instituto Estadual de Hematologia Arthur de Siqueira Cavalcanti, Rio de Janeiro, RJ, Brasil, em agosto de 2013. Seis enfermeiros foram entrevistados e utilizou-se a análise temática. Os aspectos fundamentais relacionaram-se à importância do treinamento e educação permanente, ao trabalho em equipe, aos desafios no cuidado à criança hospitalizada e às particularidades da doença, e à sistematização, ao uso de instrumentos e protocolos. Para a segurança da criança, a articulação entre a administração e assistência é fundamental, em prol da qualidade.

Descritores: Enfermagem Pediátrica; Oncologia; Segurança do Paciente; Gerência.

El objetivo fue identificar como se aplica la gestión de seguridad por enfermero en gerenciamiento de la atención de enfermería, y analizar sus desafíos en habitaciones pediátricas onco-hematológicas. Estudio descriptivo, cualitativo, llevado a cabo en el Instituto Estadual de Hematologia Arthur de Siqueira Cavalcanti, Rio de Janeiro, RJ, Brasil, en agosto de 2013. Seis enfermeros fueron entrevistados y se utilizó el análisis de contenido. Los aspectos clave se relacionaron a la importancia de la formación y educación permanente, con el trabajo en equipe, con desafíos en la atención al niño hospitalizado y a las particularidades de la enfermedad, y con la sistematización, uso de instrumentos y protocolos. Para la seguridad del niño, la articulación entre administración y asistencia es fundamental para la calidad.

Descriptores: Enfermería Pediátrica; Oncología; Seguridad del Paciente; Gerencia.

\footnotetext{
${ }^{1}$ Universidade Federal do Rio de Janeiro. Rio de Janeiro, RJ, Brazil.

${ }^{2}$ Instituto Nacional de Câncer. Rio de Janeiro, RJ, Brazil.

Corresponding author: Marcelle Miranda da Silva

Rua Afonso Cavalcanti, 275. Cidade Nova. CEP: 20211-110. Rio de Janeiro, RJ, Brazil. E-mail: marcellemsufrj@gmail.com
} 


\section{Introduction}

The nursing professional is responsible for the management of the nursing care, developing multifaceted actions which include: planning, organization and rendering care; training and delegation of activities to the other participants of the nursing team and their supervision; education of patients and family members in order to reach the targets of care; besides the interaction with the other professionals of the health team through interdisciplinary practice ${ }^{(1)}$. Among these responsibilities several objectives for the quality of the rendered care, such as the management of safety for risk prevention and damage reduction.

The thematic of the patient safety has been recently discussed in the scientific domain, more specifically from the publishing, in 1999, of the report 'To err is Human: Building a safer health care system', of the Institute of Medicine, of the United States of America. This document shows data on mortality related to errors arising from the health care, which could be avoided ${ }^{(2)}$. So, speaking about safety of the patient means to think in the reduction of risk of unnecessary damage associated to the health assistance up to an 'acceptable minimum', in order to provide safety and effective assistance to everyone ${ }^{(3)}$.

The interest of this thematic covers an area of knowledge and nursing action, which have been taking the role of precursor in the discussions of the safety of the patient ${ }^{(4)}$. In the present study, the context of pediatric nurse and its onco-hematologic specialization is highlighted.

Studies reveal that specificities in the age range can contribute to the occurrence of errors, such as, for example, in the administration of medicine, and this is the thematic focus of a greater highlight, because it is a more common form of intervention in the health care. In this case, the following factors related to childhood are considered: weight, stature, clinical conditions, characteristics of the metabolism and the scarcity of medication for this population, demanding multiple mathematical operations for the calculation of the dosage and excessive manipulation in the dilutions ${ }^{(5-6)}$. Besides that, it is also highlighted that factors concerning human failure and the high load of work significantly contribute for these occurrences ${ }^{(7)}$.

Such scientific evidences confirm the practical experiences and empirical observations made by the authors in pediatric wards, associating such intrinsic and childhood behaviors factors to a higher risk of errors or failures in the nursing assistance, also highlighting the risk of falling and infection, for example. This, once added to aspects of the onco-hematological diseases and its treatment, can require a prolonged hospitalization or a modification of the treatment, initially proposed ${ }^{(4,6)}$.

So, the hospitalized child is more vulnerable to the adverse occurrences, which can potentially jeopardize their safety. Several elements which consist in the circumstances of care can influence so that it can be safe of unsafe. Considering that such elements include the action itself (intervention, procedure, behavior), the team, the patients and his family, the context (processes of work, rules, organizational cultural) and the venue (unit of hospitalization) ${ }^{(4)}$, the importance of the nursing care in managing this care appears, fundament in the principles of safety, as well as the institutional responsibility in the actions for safety management.

Thus, the following guiding questions are presented: 'How is the management of safety in the onco-hematological wards performed according to the point of views of nurses?' 'Which factors can positively or negatively interfere in a management of safety in this scenario?'

The aim was at identifying the management of safety applied by the nurse in the scope of nursing care management, and to analyze their challenges in the onco-hematological pediatric wards.

The justification of the study is based on the contemporaneity and importance of the thematic for the quality of the nursing assistance rendered. This thematic is based in a world discussion, considering that, after the launching of the World Alliance of Pa- 
tient Safety in 2004, through Resolution in the $57^{\text {th }}$ World Health Assembly ${ }^{(3)}$, recommending the countries a greater attention to the Safety to the Patient theme, especially to under developed countries or developing countries ${ }^{(8)}$. This alliance has the aim at arising the consciousness and political commitment to improve the safety in assistance. In the national context, the safety of the patient is treated as priority of research by the health department, besides being ruled by the Director's Collegiate Resolution no. 36/2013 and by Resolution no. 529/2013 (9-11). $^{\text {. }}$

\section{Method}

It is a descriptive study, with qualitative approach, made in the Instituto Estadual de Hematologia Arthur de Siqueira Cavalcanti, which renders assistance in hematology and hemotherapy to the population and coordinates the blood related work in the state of Rio de Janeiro, Brazil. According to Resolution no. $62 / 2009$ of the Health Department, it is categorized as a Unit of High Complexity in Oncology. Besides that, it is part of the Brazilian net of sentinel hospitals, created in 2001, which is a strategy of the National Health Surveillance Agency, which consists in teaching and/or high complexity hospitals, to act as active observatories of the development and safety of health products regularly used, such as: medicine, laboratory exam kits, prosthesis, equipment and medical hospital supplies, disinfectants, blood and its components ${ }^{(12)}$.

The technique of data collection used was the semi-structured interview, following this guideline: how were you informed on the existence of the guidelines of the safety management institutionally defined for the nursing assistance practice? How is the implementation of that guideline put into practice in the onco-hematology pediatric wards? Which factors can positively or negatively interfere in that implementation?

Six nurses, out of eight, participated in the study, from which consisted the personnel of human resources of the pediatric wards, once one was under medical leave and another on vacation in the period of data collection, which corresponded to the month of August 2013. Such participants complied with the following criteria of inclusion: to have a work contract with the institution and act in the onco- hematology pediatric ward at the moment of the data collection.

The interviews were made individually, during the most convenient time during the shift, in a reserved room. The contents of the interviews were recorded, in accordance with the participants, in an e-recorder and later on, totally transcript. The data were analyzed through thematic analysis, consisted of three stages: pre-analysis, exploration of the material and interpretation of the results ${ }^{(13)}$, which was complemented based in the revision of the literature and the critical view of the authors.

Respecting ethical aspects of research with human beings, according to Resolution no. 466/2012 of the National Council of Health, the project of research was approved by the Committee of Ethics and Research of the Anna Nery Nursing School, as the proposition institution, with Legal Opinion no. 229/972, as well as by the Committee of Ethics in Research of the Instituto Educacional de Hematologia Arthur Siqueira Cavalcanti, as a co-participant institution under Legal Opinion no. 330/13. All the nurses signed the Free Inform Consent Form and their statement were identified with the letter N, for nurse, followed by an Arabic number, in order to keep secrecy and anonimaty of the information, according to the examples: N1, N2, N3.

\section{Results}

The results pointed fundamental aspects related to the importance of the training and permanent education in the services; such as the team work and participation of the family, and the recognition of the challenges in the care to the hospitalized child, especially concerning the particularities of the onco-hematological diseases, their treatment and risk of falling. Such aspects are presented as follows. 


\section{The safety management in the scope of the mana- gement of the nursing care}

The statements value the importance of the training and permanent education in order to reach good standards of safety. For example, the following issues were approached: the importance of the training in the admission of the employee, in order to contemplate the demands during the new admissions. So, in the act of admission, we received several trainings, such as the safety of work, fight against fires, without taking into consideration that we work according with the NR-32 Rule and the standard operations procedures, which are the procedures that guide our practice, and here we have several of those (N1).

As to the presentation of the Standard Operational Procedures, the superficiality is highlighted, and their existence are many times to comply with the bureaucratic and legal requirements once, according to the nurses, we know that protocols exist, which are made available, if I'm not mistaken through the internet, and we also have here in the pediatrics wards a file with all of them, but people use it too little, including myself (N6).

So, it is important to verify the needs of the health professional in order to make permanent education available, once the routine many times consume them, without providing time for a deep knowledge of the conceptual basis which guides practice. This has been a concern of the institution, considering the approach of the statutory workers, and other originated from other employing sources. We have a continued well working educational sector, now with the company we render service for, the health foundation, they also try to offer courses and everything else. They have not yet offered risk management but it's a project. I think the institution tries to guide us well, so this is quite positive (N1).

The thematic of the safety management concerning the peculiarities of the nursing care in it has not yet been completely treated in the scope of permanent education, so the nurses approach general questions regarding the safety of the environment, as well as some specific aspects which are linked to the child care. In this case, my boss passed all the routine work on to us, then she passed the protocol of risk of falling. Once, I remember that she came here with an employee of the fire brigade, and he had training with us at night on how to act in a case like this, for example (N6).

So, among the risks which are present during hospitalization, the nurses emphasize the risk of falling, once this theme is quite discussed in the sector, with one stablished routine for its assistance and management. Therefore, there is a standard instrument which evaluate this risk. The instrument must be filled in during the admission of the child and weekly reevaluated, including orientations passed on to the accompanying person who signs a term agreeing with the awareness of such risk and the due care. The great risk of the child is the risk of falling, because the child is hyperactive, and they don't have certain understandings nor the obligation to have that. So, our risk is always high (N3).

Considering the managerial dimension of the working process of the nurse, it appears from this statement the need of attention to the environment and the role of the manager, which must also be reproduced by the other nurses in order to reach all the participants of the nursing team. And in the daily routine, it is possible to identify the group and the individual needs.

Considering the influence of the human factor in taking care, it is also highlighted the possibility of error, which is followed through the statement by the same employee when notifying the occurrences. There is an instrument, in case there is a mistake, or any serious intercurrence such as in the case of an error in the administration of medicine, or even to obtain data to help in the intervention. So, errors of administration in medication, fall of the patient or any other problem, we can notify (N5).

During the measures to avoid errors, the action of orientating the parents who work as a helping tool in the safety management is highlighted, once both the health team as well as the family members is committed in the recovery of the health of the child. We always verify if the mothers have been orientated, until the child is a little older. And when the accompanying person is participative he tries to know everything, and knows the number of enrolments by heart (N2).

Generally, it is necessary to value the systemati- 
zation of the actions and the register for the safety management, once, although people have differentiated levels of experience, each one has his way, but the basic must be made the same way (N5).

\section{The challenges of safety management of the hospi- talized child with hematologic cancer}

The context of acting of nursing in pediatrics demands a differentiated look due to the behavior of the child, once many times they do not perceive the situation of the disease which attacks them, increasing their exposition to several risks. The very young child loose kite with equipo, for example, she plays kicking the support, so, we have to always observe and talk (N4).

The continuous attention is a factor able to contribute to the reduction of the risks to which the children are exposed, which can be made easier through the work in a team and in a partnership with the accompanying members. In the case of the establishment of a partnership with accompanying members, problems can be experienced. Not always a better accompanying member who has the best relationship with the child is the one who can stay here. So, there are cases in which you can talk with the accompanying member very well and orientate him, whereas with others this doesn't work very well, whether because the child does not respect him, or because he is not so patient. There are some parents that we talk with, orientate them, and when we leave, they leave the child alone in the cradle and don't communicate us (N2).

In any case, it is highlighted that the nurse needs to stablish effective communication towards the partnerships, considering the difficulties of each family member in the understanding of the information on the safety and the health condition of the child. Actually, there are positive experiences, when, without any doubt, we manage to provide specific orientation for the parents which avoid some kind of disease, or complication which the hospital environment may cause for the child (N6).

The peculiarities of the clinical condition of the child were approached as one of the great challenges in the safety management. There are children who stay here hospitalized for 90 days, so the longer they are exposed to the hospital environment the greater the risks are, whether regarding falling or drug leakage, for example. Something that is very peculiar in the onco-hematology is the use of chemotherapy medicine; they are more vulnerable than a child who is in a pediatric ward using a bronchodilator, or treatment some other diseases which is prevalent in childhood. So, here the child generally has a profound access and makes use of more specific medicine which are generally seen inside an Intensive Therapy Uni, which is the case of the amphotericin B. So, in this kind of medication the gravity of adverse events can be infinitively greater (N6).

When approaching the aggressiveness of the treatment, specific of chemotherapy, despite the fact that interviewed nurses are not directly responsible for the administration of such medicine, they emphasize the team work. In the case of chemotherapy we do not install them, for example, but we work together with the team who is responsible for the occasional risk of extravasation or if some adverse event happens (N6).

So, the peculiarities related to the time of hospitalization, to the disease and its treatment are directly related to the risks and need to be managed. However, besides the difficulty in the establishment of partnership with the accompanying person in some cases, the nurses also raise the question of the difficulty of team work, for they see themselves with this concentrated responsibility. I think that only a health professional can make an effort of the orientation and it is a little complicated, not that this is not our responsibility, because sometimes we have several other things to do and we get overloaded, they are functions attributed here only to the nurse, but I now that is important. I think that it would be very interesting if a meeting was asked with a multidisciplinary team with these mothers, [...] there is a lot to do just for the nursing professionals as if only the nurses would worry with the safety of the patient and actually the whole multidisciplinary team should be worried with this (N2).

Facing the need of systematization of the actions and register, whether they are clinical indicators of notification of errors, one of the great challenges to this practice is to alert on the character of this action, once that even knowing that some safety measures regarding the material, its quality, to some adverse event which happened with the child regarding the medication must be notified, and this is rare, I particularly do not remember, the health professional thinks that notifying an error is to accuse someone or himself which actually it is not. Everything is for the welfare of the patients (N6). 


\section{Discussion}

Several actions were highlighted by the nurses when managing the nursing care aiming at the reduction of the risk of damages to the hospitalized child. Among these, at first, there is the need of training and permanent education, identifying it with the results of other researches ${ }^{(4-6)}$.

The permanent education must be used as a managerial tool to improve the professional performance, contributing for infective and safe practice, as well as being an instrument able to maximize the interpersonal relations in the nursing work.

According to the Health Department the process of education of the health professionals must be guided from the problems based on the reality experience by them, covering problems and challenges. So, the importance of feeding the indicators which follow the risks is highlighted as well as the adequacy in the notifications of the occurrences as one of the ways of surveying the need of training. Stablishing the immediate, subjacent and latent factors which took to failures in the occurrences demands their identification and analysis in order to prevent recurrences, and it is preponderant to focus on these facts and avoid the counterproductive blame on the others ${ }^{(14)}$. Nevertheless, there is the challenge of the register of such occurrences when related to human error.

The National Policy of Permanent Education in Health proposes to invert the logic of the process from the practice as a source of knowledge and problems, besides placing the people as reflexive actors of the practice and constructors of knowledge, instead of just being receptors ${ }^{(15)}$. The existence of the permanent education is reinforced by the fact that nursing is a profession that does not exist without the collective cooperation, without the team work, which searches the achievement of the assistance and the care to the health of the human being.

However, to preserve the safety of the patient it is essential to deconstruct the notion that the failure is individual, enhancing the focus of the responsibility for the adverse event. The occurrence of the adverse event can be related to intrinsic and extrinsic aspects related to the profile of the clientele, to the human failure, and to the institutional context ${ }^{(5)}$. The development of the culture of safety is essential and will occur through the conception of team and collective work, thus eliminating the strong culture of punishment still existent in the hospital institution ${ }^{(16)}$.

So, it is extremely important that the multidisciplinary team has the objective to make the period of hospitalization as little traumatic as possible. However, special dedication of nursing is regarded to the character of their actions and to the time spent with the children, once they are professionals who spend 24 hours present during their hospitalization.

Furthermore, the updating and technological capacitation developed by the processes of permanent education is fundamental, once knowledge is one of the main tools the health professionals have to guarantee safe and high quality care to the patients ${ }^{(17)}$.

In the assistance area of the process of work of the nurse education is considered an important theme, once all the actions are related to educational practice. In this case, the work of orientation of the accompanying person is valuable, through effective communication and identification of particular needs. The presence of the family members is extremely important, once it is one of the main components to cope with the situation of the disease by the child. Ant the binomial child/family must be taken care of, once all of them are directly affected in several instances of their daily activities, especially with the hospitalization.

When searching partnerships with the accompanying members for the establishment of measures to maintain the safety of the child, and considering the risk of fall, the nurse must keep in mind that the focus of the existence is not just turned towards the child, but, as a way to contextualize care, and this includes the family. This behavior also contributes to minimize the negative feelings experienced by the child and increase their feeling of being protected and having 
their individuality ${ }^{(18)}$. So, the education based in the exchange of information and experiences between the family member and the nurse is one of the instruments of care to the hospitalized child. Rendering a quality and safe care facing so many areas becomes a challenge for nursing, once it is necessary, to identify and understand the needs of the parents and integrate them to care, when not always the desired results are obtained $^{(19)}$.

Some problems can be identified in the relation between the child and the accompanying person, as well as in his behavior when starting the function. The nurses highlight situations where the accompanying members have no patience or authority with the child, besides the difficulty of communication between them and the nursing team.

In the relation between the accompanying member and the nursing team it is necessary to be conscious of the responsibility of both of them in the care, however, considering that the mother, for example, can help with the care provided to her child, once she wants this and feels she is able to do it at that moment. So the nursing professionals must not perceive the mother as an agent of work, once her presence is essential for the recovery of the child being a support of their emotional needs ${ }^{(18)}$.

The frequent change among the accompanying members of the child needs to be taken into consideration for the nursing care, when judging that the actions of orientation, training and clarifying doubts must happen daily, in a way that all the accompanying members can feel more secure during their stay in the hospital ${ }^{(20)}$. This is an aspect which can generate overload to the nursing team, besides the mentioned difficulty in work in an interdisciplinary way aiming at the safety management.

So, the overload on the nursing team can be explained by the fact that these health professionals are the ones who stay longer beside the patients and their accompanying members. So, besides rendering clinical care, the nurse is involved and tries to take complete care assisting the needs beyond the physical aspect, which requires a lot of communication and dedication of time, once the hospitalization is long, providing a longer experience and the creation of bonds, thus leading, the nurse, the child and the family members to share experiences of the everyday activities, emotions and feelings ${ }^{(21)}$.

When one works in pediatrics he must highlight the matter of psychological tiredness, once the child sometimes does not understand that there is a routine in the hospital, besides the fear and tension that emerge when it is needed to perform exams or procedures. So, the nurse must be prepared to talk and convince the child to collaborate, which requires patient and comprehension of the nurse during his period of work. Such care is considered as sources of risk for the safety, both of the patients as well of the nursing team, because they also unleash physical tiredness, thus provoking overload ${ }^{(7,22)}$.

It is fundamental that the whole multidisciplinary team recognizes the existing link among the several activities performed, so that they can integrate their actions. There must be a search and articulations of actions and integration of the professionals. When aiming at the safety management in the investigated context, this type of work makes the early identification of the risk or the problem easier, in order to reduce damage.

As peculiarities of the context, the nurses emphasize, besides the child's own behavior and her difficulty in recognizing the danger and the limits, which the oncological disease and its treatment expose the child excessively, this being one of the factors responsible for the prolonged hospitalization, as it can be observed in other studies ${ }^{(4,6)}$.

Regarding the risk of falling, it is known that this occurrence is very frequent in the hospitals and can have physical, psychological and social consequences. From the report of the nurses it was possible to identify the peculiarities which make the hospitalized child more vulnerable to falling, such practice is guided by the use of an institutionally standard instrument. Because the evaluation of the risk of falling 
is made weekly, besides following the evolution of the child it is possible to reinforce the orientation to the accompanying members according to the picture they have presented, once during hospitalization the risk factors can be modified, always requiring new orientation.

Besides this manner of management of the risk of falling, there are other principles of safety to reduce it, as follows: the team action in order to create safe environment; the focus on the systemic approach for the promotion of the safety of the patient with the elaboration of systems to identify errors, enabling the team to learn with them; the direction of specific actions and development of guidelines of actions of care, which can be made in the scope of the process of nursing in dealing with this risk as a nursing diagnosis, thus being possible, the coordination of actions of intervention and evaluation for the reduction of the risk of fallen ${ }^{(5)}$.

Concerning the development of partnership, through the approach by part of the nursing team, the parents begin to actively participate in the process of hospitalization, developing attitudes which try to soften that moment for their child. The knowledge on the disease and the condition of the child is extremely important for these parents, once the feelings of insecurity, impotence and guilt can be minimized through the orientation, counseling and the clarifying of doubts $^{(22-23)}$.

The care of the patient with cancer is become each time more common in acute and critical units, so it is indispensable that the nurses are prepared to answer the unique necessities of each patient ${ }^{(24)}$. The hospitalized child with onco-hematological disorder is submitted to several evasive procedures due to the treatment, among them the venous access, which is constantly threatened by the behavior of the child, besides the risk of infection, especially in the case of central accesses. There are also, other factors which make this procedure difficult, as follows: the condition of the chronical disease and itself, prolonged intravenous therapy, use of vesicant and/or irritating drugs and previous hospitalization. Regarding the behavior including games, which are inherent to the child, it should be highlighted that it must be accepted by the team as normal, once playing in the context of the hospitalization, allows the child to perceive the possibilities of coping and so develop adaptive behavior.

Facing such peculiarities, when performing procedures on these children it is necessary skills, with great technical ability, sensibility, empathy, patience and knowledge on their clinical situation. Such requirements demand availability of time, and so, it is indispensable that the processes of work are well organized and developed in team, once the excessive load of work is an important cause for the occurrence of adverse events and human errors caused by hurry ${ }^{(7)}$.

So, the existence of Standard Operational Procedures was highlighted in the investigated scenario, which try to help the assistance of behaviors in the performance of specific care, although their disclosure do not always reach acceptable levels. So, the training based on the practice of case studies is valuable, for example. Besides the little access to the Standard Operational Procedures, another factor which can contribute for the difficulty of notification of the occurrences is the lack of knowledge on how to precede, difficulty of identification and quantification of the problem or fear of suffering some punishment ${ }^{(25)}$.

It is highlighted that the indicators and the notifications of occurrences are not only a tool of control, but specially, a systemized manner to better understand and know the organizational reality. Therefore it is necessary to adjust the communication and the integration among the agents involved in the assistance, in order to build consensus and agreements, which enable the health professionals to systematize a common assistance project, where the objective is to render the best possible assistance ${ }^{(25)}$. 


\section{Conclusion}

Through the analysis of the data, it was evident that the main managerial tools for the management of safety in the environment of the nursing wards of onco-hematology pediatrics were: valuing training and permanent education; team work and participation of the family in order to increase surveillance on the child considering the fact that their behavior can increase the risk, whether related to falling or to the loss of the venous access and infection, for example; and systematization of the actions with adequate notification of the occurrences and use of Standard Operational Procedures according to the needs of service.

The recognition of the challenges is fundamental, especially concerning the particularities of the onco-hematological disease, its treatment and prolonged hospitalization. The risk of falling showed to be the best indicator in the context, once it uses standard scale and frequency in their evaluation.

However, the register of other errors, especially human errors, is a challenge, once it is related to the exposition and possibility of punishment to those who practice it, without considering the participation and responsibility of everyone in maintaining security. So, another point discussed is concerning the need of a greater multi professional performance with this objective, that is, to have a better integration among all the participants of the team in the management of security.

The importance of the accompanying members is highlighted, reducing the fear of the children in this new and many times frightening environment. Therefore, taking care of children with onco-hematological disorders goes beyond the technical care of nursing, it is necessary to have a differentiated look covering the bio-psychosocial needs of the children and their family. Each family must be considered unique and with singular needs, and the management of conflicts in the relation between the family and the nursing team must have a good ability of communication and persistence in information, which tries to keep the se- curity and the reduction of damage to the health of the child.

Covering all the dimensions of the process of work of the nurse, it is indispensable that he is organized and let the staff work as a team, once the excessive load of work is an important cause for the occurrence of adverse events and human errors. So, the systematization and the register of assistance in a standard manner are elements which cooperate for a safety management of quality, with good indicators, and it is necessary to the nurse do develop and improve his abilities in the area of administration in nursing, enhancing his vision, associating cognitive, environmental, relational and organizational elements.

\section{Collaborations}

Silva MMS contributed for the orientation, analysis, interpretation of the data, conception of the work and writing of the article. Curty BIC contributed in the data collection, analysis and interpretation of the data and writing of the article. Duarte SCM contributed in the interpretation of the data, conception of the work and writing of the article. Zepeda KGM contributed with the interpretation of the data and writing of the article.

\section{References}

1. Christovam BP, Porto IS, Oliveira DC. Nursing care management in hospital settings: the building of a construct. Rev Esc Enferm USP. 2012; 46(3):72935.

2. Kohn LT, Corrigan JM, Donaldson MS, editors. To err is human: building a safer health system. Washington D.C.: National Academy Press; 2000.

3. World Health Organization. World alliance for patient safety: the conceptual framework for the international classification for patient safety. Geneva: WHO; 2009.

4. Wegner W, Pedro ENR. Patient safety in care circumstances: prevention of adverse events in the hospitalization of children. Rev Latino-Am Enfermagem. 2012; 20(3):427-34. 
5. Harada MJCS, Chanes DC, Kusahara DM, Pedreira MLG. Safety in medication administration in pediatrics. Acta Paul Enferm. 2012; 25(4):639-42.

6. Belela ASC, Pedreira MLG, Peterlini MAS. Erros de medicação em pediatria. Rev Bras Enferm. 2011; 64(3):563-9.

7. Sears K, O'Brien-Pallas L, Stevens B, Murphy GT. The relationship between the nursing work environment and the occurrence of reported pediatric medication administration errors: a pan Canadian study. J Pediatr Nurs. 2013; 28(4):351-6.

8. Jha AK, Prasopa-Plaizier N, Larizgoitia I, Bates DW. Patient safety research: an overview of the global evidence. Qual Saf Health Care. 2010; 19:42-7.

9. Ministério da Saúde (BR). Agenda nacional de prioridades de pesquisa em saúde. Brasília: Ministério da Saúde; 2008.

10. Ministério da Saúde (BR). Resolução da Diretoria Colegiada n. 36 de 25 de julho de 2013. Institui ações de segurança do paciente em serviços de saúde e dá outras providências. Brasília: Ministério da Saúde; 2013.

11. Ministério da Saúde (BR). Portaria n. 529 de 1ํㅡㄴ de abril de 2013. Institui o Programa Nacional de Segurança do Paciente (PNSP). Brasília: Ministério da Saúde; 2013.

12. Agência Nacional de Vigilância Sanitária (BR). Estratégias para segurança do paciente em hospitais e clínicas. Brasília: ANVISA; 2010.

13. Bardin L. Análise de Conteúdo. São Paulo: Editora Geográfica; 2010.

14. Peixoto LS, Gonçalves LC; Costa TD, Tavares CMM, Cavalcanti ACD, Cortez EA. Permanent, continuous and of use education: revealing its concepts. Enferm Glob. 2013; 29:324-40.

15. Ministério da Saúde (BR). Conselho Nacional de Saúde, Secretaria de Gestão do Trabalho e da Educação na Saúde. Política Nacional de Educação Permanente em Saúde. Brasília: Ministério da Saúde; 2009.
16. Reason J. Human error. London: Cambridge University Press; 2003.

17. Rigobello MCG, Carvalho REFL, Cassiani SHB, Galon T, Capucho HC, Deus NN. The climate of patient safety: perception of nursing professionals. Acta Paul Enferm. 2012; 25(5):728-35.

18. Quirino DD, Collet N, Neves AFGB. Child hospitalization: nursing conceptions about mother's companion. Rev Gaúcha Enferm. 2010; 31(2):300-6.

19. Murakami R, Campos CJG. Importance of interpersonal relationship of the nurse and the family of hospitalized children. Rev Bras Enferm. 2011; 64(2):254-60.

20. Gomes IP, Amador DD, Collet N. The presence of family members in the pediatric chemotherapy room. Rev Bras Enferm. 2012; 65(5):803-8.

21. Mutti CF, Padoin SMM, Paula CC. Spaciality of being-nursing-professional in the world of caring to children who has cancer. Esc Anna Nery. 2012; 16(3):493-9

22. Duarte MLC, Zanini LN, Nedel MNB. The daily routine of parents of children hospitalized with cancer: nursing challenges. Rev Gaúcha Enferm. 2012; 33(3):111-8.

23. Silva TCO, Barros VF, Hora EC. Experience of being a family caregiver in childhood cancer. Rev Rene. 2011; 12(3):526-31.

24. Luanne LP. The use of simulation for pediatric oncology nursing safety principles: ensuring competent practice through the use of a mnemonic, chemotherapy road maps and casebased learning. J Pediatr Nurs. 2012; 27(3):283-6.

25. Souza S, Rocha PK, Cabral PFA, Kusahara DM. Use of safety strategies to identify children for drug administration. Acta Paul Enferm. 2014; 27(1):611. 